\title{
STRUCTURAL CHARACTERIZATION OF THE THERMAL EVOLUTION \\ OF TETRAHEDRALLY COORDINATED AMORPHOUS CARBON FILMS
}

SAND- $97-167 / C$

L. J. MARTINEZ-MIRANDA*, J. P. SULLIVAN, T. A. FRIEDMANN, M. P. SIEGAL**, AND N. J. DINARDO***

CONF- $97 / 201 \cdots$

*Dept. of Materials and Nuclear Eng., University of Maryland, College Park, MD 20742-2115, martinez@eng.umd.edu

**Sandia National Laboratories, Albuquerque, NM 87185

***Dept. of Physics and Atmospheric Sciences, Drexel University, Philadelphia, PA 19104; Dept. of Materials Science and Engineering, University of Pennsylvania, Philadelphia, PA 19104

\section{ABSTRACT}

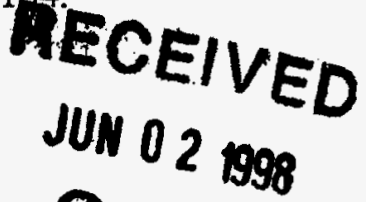

We present the results of a post-deposition annealing structural study on amorphous tetrahedrally-coordinated carbon (a-tC) films on $\mathrm{Si}(100)$ prepared by pulsed-laser deposition. Films as-deposited and post-annealed at $200,300,400,500$ and $600{ }^{\circ} \mathrm{C}$, respectively, are studied using combined $\mathrm{x}$-ray reflectivity and low-angle scattering measurements. The scans are fit to the Fresnel equations to obtain values for average film density, film and interface thickness, and film and interface roughness. We observe a correlation between the evolution of film density, roughness and the spacing of quasi-periodic structures in the films as a function of annealing temperature. We relate the evolution of these structural features with previous measurements of the resistivity and the observed stress release in these films.

\section{INTRODUCTION}

Amorphous tetrahedrally-coordinated diamond-like carbon (a-tC) films are of interest due to their high thermal stability, good tribological properties and low-electric field cold-cathode emission. A significant drawback for the use of these films in electronic applications is the several GPa high residual compressive stress present in as-grown films. Sullivan et al. reported recently that thermal annealing to $600{ }^{\circ} \mathrm{C}$ of a-tC films grown by pulsed laser deposition (PLD) reduces the as-grown film stress to negligible levels and that some stress reduction occurs at annealing temperatures as low as $100^{\circ} \mathrm{C}$.[1]

The above study also showed that stress reduction occurs without changing significantly the optical transparency or the electrical resistivity of the films. Other work on amorphous carbon (a-C) films indicated that a-C density decreases with increasing annealing temperature.[2] In this paper, we present the results of a structural evolution on a-tC films on $\mathrm{Si}(100)$ prepared using PLD and subsequently annealed for two hours at temperatures ranging from room temperature to 600 ${ }^{\circ} \mathrm{C}$. The evolution is studied using a combination of $\mathrm{x}$-ray reflectivity and small angle scattering. The films exhibit a decrease in density with increasing annealing temperature, similar to the one exhibited by a-C films. In addition, the films exhibit an evolution in both surface and interface roughness with annealing temperature. A small angle scattering signal, observed as a function of deposition energetics in similarly prepared samples changes position as a function of temperature.[3,4] 


\section{EXPERIMENTAL}

We use PLD to grow a-tC films onto $\mathrm{Si}(100)$ wafers from a rotating pyrolytic graphite target with $248 \mathrm{~nm}$ excimer pulsed-laser radiation $(\mathrm{KrF})$. The details of the deposition process are similar to those described elsewhere.[5] Films nominally $90 \mathrm{~nm}$ thick are grown in a vacuum chamber with base pressure $<10^{-7}$ Torr with laser energy density $=45 \mathrm{~J} / \mathrm{cm}^{2}$. The Si substrates are precleaned with acetone, methanol, and a brief immersion in dilute HF prior to deposition. Post-deposition thermal annealing is performed using a commercial rapid thermal processing system in 630 Torr Ar gas (atmospheric pressure in Albuquerque, NM) in a fused silica chamber with external heating lamps. Similar a-tC films are thermally treated at temperatures ranging from 200 to $600{ }^{\circ} \mathrm{C}$ for two hours each. Two hour anneals were found to saturate the stress relief for a given temperature.[1]

The $\mathrm{x}$-ray studies were performed using the $\mathrm{Cu} \mathrm{K}_{\alpha 1}$ radiation from an $18 \mathrm{~kW}$ rotating anode source with a resolution of $0.0001 \AA^{-1}$. The resulting reflectivity curves were fit to the Fresnel interference curve for a film of finite thickness $d$. The small angle signals were fit to Gaussian curves. The resulting fit allows us to extract information on the density, the roughness and the thickness of the films, as well as the position evolution of the small angle signal.

\section{RESULTS AND DISCUSSION}

Figure 1 shows the $\mathrm{x}$-ray reflectivity data obtained from an as-grown a-tC film as well as films annealed at $200,300,400,500$ and $600{ }^{\circ} \mathrm{C}$ respectively. In addition to the characteristic reflectivity curve, all the films exhibit a diffraction peak about $2 \theta=2^{\circ}$, which changes position as a function of annealing temperature. Figure 2 shows the superposition of the reflectivity from the as-grown sample and from the sample annealed at $200{ }^{\circ} \mathrm{C}$. We notice an increase in the near surface roughness in the sample annealed at $200^{\circ} \mathrm{C}$.

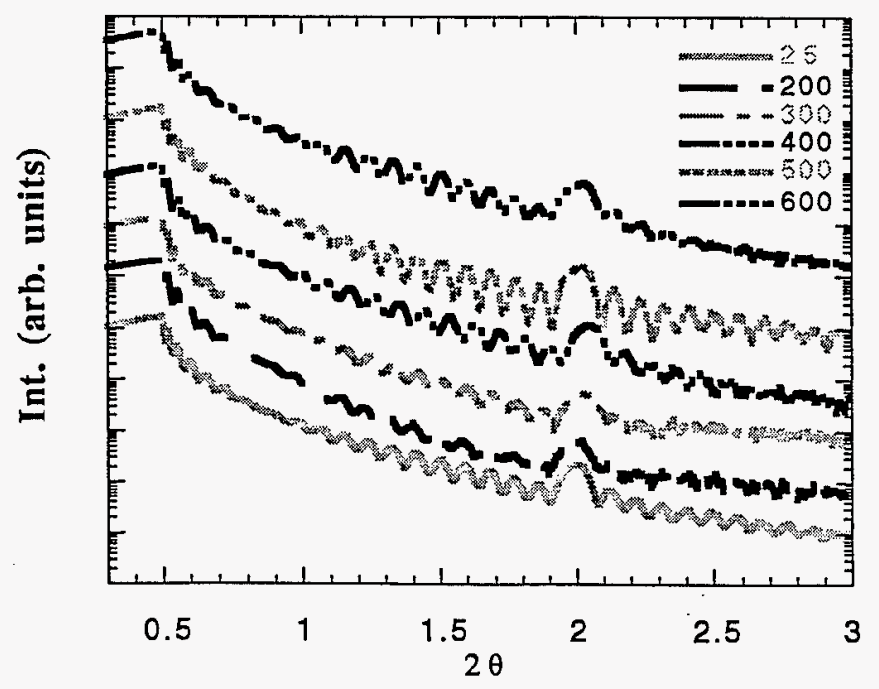

Figure 1. X-ray reflectivity curves obtained from the temperature annealed samples. The curves have been displaced along the ordinate for clarity. 


\section{DISCLAIMER}

This report was prepared as an account of work sponsored by an agency of the United States Government. Neither the United States Government nor any agency thereof, nor any of their employees, makes any warranty, express or implied, or assumes any legal liability or responsibility for the accuracy, completeness, or usefulness of any information, apparatus, product, or process disclosed, or represents that its use would not infringe privately owned rights. Reference herein to any specific commercial product, process, or service by trade name, trademark, manufacturer, or otherwise does not necessarily constitute or imply its endorsement, recommendation, or favoring by the United States Government or any agency thereof. The views and opinions of authors expressed herein do not necessarily state or reflect those of the United States Government or any agency thereof. 
The reflectivity curves are fit to a function,

$$
I=f\left(R_{j}(\theta), \exp \left(-\sigma_{j}^{2} q^{2}\right)\right)+\Sigma A_{i}^{*} G\left(q_{i}\right)
$$

where $R_{j}(\theta)$ is the Fresnel reflectivity curve of a film with two interfaces, $\sigma_{j}$ is the roughness of the interfaces, $q$ is the scattering wavevector, $A_{i}$ are constants and $G\left(q_{i}\right)$ is a Gaussian function of width $\Delta$ q.[6] The function $f\left(R_{j}(\theta), \exp \left(-\sigma_{j}^{2} q^{2}\right)\right.$ ) describes the reflectivity of a number of multilayers. All films are fit to two Gaussians, centered about $0.05 \AA^{-1}$, and $0.14 \AA^{-1}$ respectively. The films annealed at $500^{\circ} \mathrm{C}$ and $600^{\circ} \mathrm{C}$ were also fit to a multilayer reflectivity curve. Table I shows the values obtained for the density $\rho$, the film roughness $\sigma$, and the position of the small angle peak obtained from the fits.

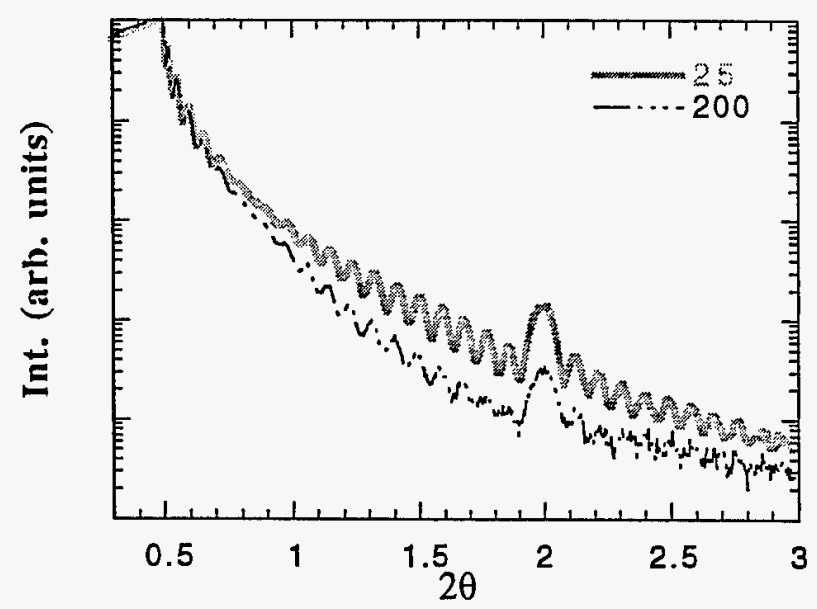

Figure 2. Comparison of the reflectivity curves for the as-grown film and the film annealed at $200{ }^{\circ} \mathrm{C}$. The faster decay of the curve for the $200^{\circ} \mathrm{C}$ film indicates increased roughness.

Table I. Structural properties of a-tC films as a function of annealing temperature, obtained from the fit to equation 1.

$\underline{\mathrm{T}_{\mathrm{a}}\left({ }^{\circ} \mathrm{C}\right) \text { density }\left(\mathrm{g} / \mathrm{cm}^{3}\right)}$ roughness $(\AA)$ small angle feature spacing $(\AA)$

\begin{tabular}{llll}
\hline 25 & 3.01 & 0.0 & 44.19 \\
200 & 3.00 & 9.0 & 43.91 \\
300 & 2.95 & 6.0 & 43.56 \\
400 & 2.86 & 2.0 & 43.12 \\
500 & 2.81 & 2.0 & 43.61 \\
600 & 2.79 & 0.0 & 43.78
\end{tabular}


Table I shows that the roughness of the film increases from being atomically smooth [7] for the as-grown film to a magnitude of approximately $1 \mathrm{~nm}$ at $200{ }^{\circ} \mathrm{C}$, and then decreasing monotonically above this temperature. Atomic smoothness is recovered by $600{ }^{\circ} \mathrm{C}$.

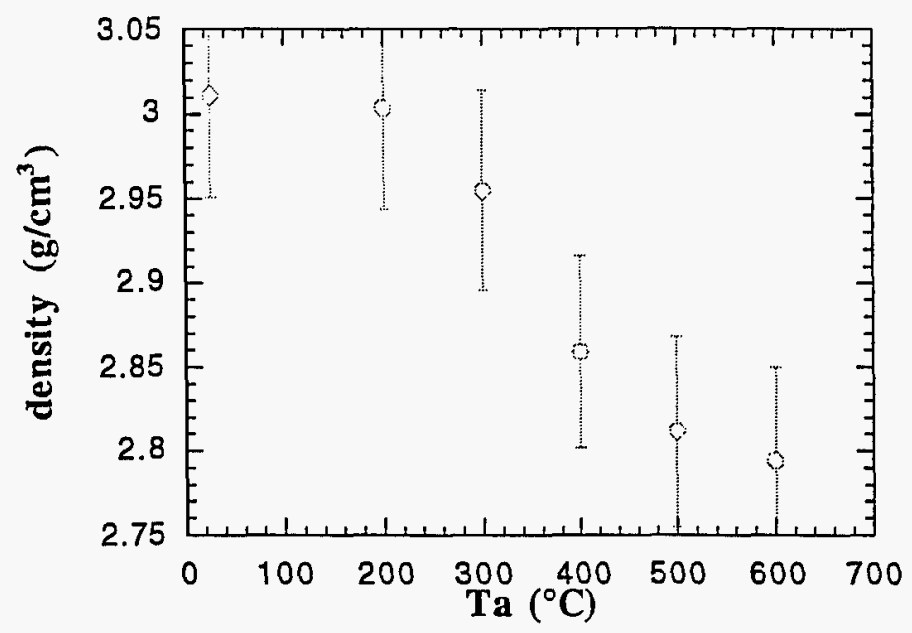

Figure 3. Mass density of the films as a function of annealing temperature, determined from equation 1.

The shape of the reflectivity curve is also affected by the presence of a small scattering peak near $2 \theta=2^{\circ}\left(q=0.14 \AA^{-1}\right)$, present in all samples. The feature is related possibly to a quasiperiodic array of scattering sites with a spacing in the order of $4 \mathrm{~nm}$. This feature may have its maximum slightly off the reflectivity axis. The spacing corresponding to this feature changes as a function of annealing temperature, as observed in Figure 1 and Table I. It achieves its smallest value at $400{ }^{\circ} \mathrm{C}$, the same temperature at which the magnitude of the changes in resistivity and density decrease. The decrease in the spacing value correlates with the increase in film roughness observed in these films: the increase in spacing observed above $400{ }^{\circ} \mathrm{C}$ coincides with the recovery of atomic smoothness in the samples. This feature has been observed previously in the study of a$\mathrm{tC}$ as a function of PLD growth energetics.[3] A report on the evolution of this feature as a function of these growth energetics will appear elsewhere.[4] We note that no evidence for the presence of crystalline structure is observed with high-resolution transmission electron microscopy,[8] and that Rutherford backscattering spectroscopy and elastic recoil detection analysis find no evidence for the presence of impurity concentrations to $0.01 \%$ atomic levels.

The evolution in roughness and position of the small angle feature as a function of annealing temperature are related apparently to changes in the films' structure associated with the increase in the ratio of 3-fold to 4-fold coordinated carbon atoms, although this change has been estimated to be a few percent.[1] Other changes contributing to the observed variations are changes at the carbon-substrate interface as the result of the annealing temperatures, as well as the evolution of interfacial layers as a function of temperature. Evidence for the latter is the fact that the films annealed at $500^{\circ} \mathrm{C}$ and $600^{\circ} \mathrm{C}$ are fit equally to a multilayer model. 


\section{CONCLUSIONS}

We have studied structural evolution of a-tC films grown using PLD and annealed to 600 ${ }^{\circ} \mathrm{C}$ using $\mathrm{x}$-ray reflectivity and small angle $\mathrm{x}$-ray scattering. The films' density decrease correlates with the resistivity decrease and stress release observed previously in similarly annealed films. The films' roughness and small angle features reflect changes in the ratio of 3-fold to 4-fold coordinated carbon as well as interfacial evolution in the films.

\section{ACKNOWLEDGMENTS}

This work was supported through Sandia National Laboratories, and an internal UMCP grant. Sandia is a multiprogram laboratory operated by Sandia Corporation, a Lockheed Martin Company, for the United States Department of Energy under Contract DE-AC04-94AL85000. We also thank Prof. S. Kumar from the Dept. of Physics and Liquid Crystal Institute at Kent State University for allowing us the use of the $18 \mathrm{~kW}$ rotating anode source, and Dr. Y. Shi, from Kent State University, for assistance in setting up the reflectivity experiments and for the use of the analysis routine.

\section{REFERENCES}

1. J. P. Sullivan, T. A. Friedmann, D. R. Tallant, J. Mikkalson, D. J. Rieger, A. G. Baca and L. J. Martínez-Miranda, Appl. Phys. Lett., in press, 1997; J. P. Sullivan, T. A. Friedmann, and A. G. Baca, J. of Elec. Mats., 26, 1026 (1997).

2. Y. Huai et al., Appl. Phys. Lett., 65, 830 (1994).

3. L. J. Martínez-Miranda, J. P. Sullivan, T. A. Friedmann, M. P. Siegal, T. W. Mercer and N. J. DiNardo, Mat. Res. Soc. Symp. Proc., 383, 459 (1995).

4. M. P. Siegal, L. J. Martínez-Miranda et al., in progress (1998).

5. M. P. Siegal, T. A. Friedmann, S. R. Kurtz, D. R. Tallant, R. L. Simpson, F. Dominguez and K. F. McCarty, Mat. Res. Soc. Symp. Proc., 349, 507 (1994).

6. Yushan Shi, unpublished; see also, M. F. Toney and S. Brennan, J. Appl. Phys., 66, 1861 (1989); C. A. Lucas et al., Appl. Phys. Lett., 59, 2100 (1991).

7. T. W. Mercer et al., Mat. Res. Symp. Proc., 358, 863 (1995).

8. J. P. Sullivan and P. P. Newcomer-Provencio, unpublished. 

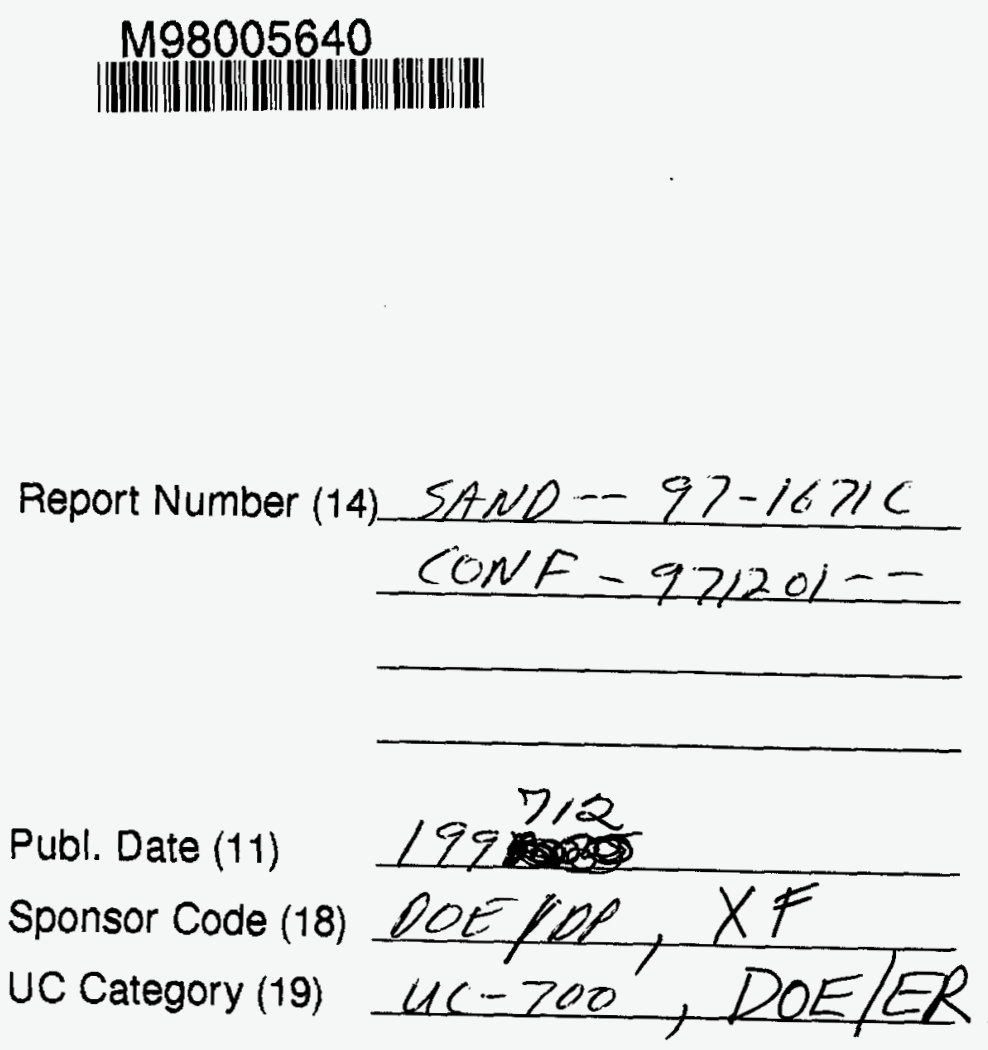

19980706098

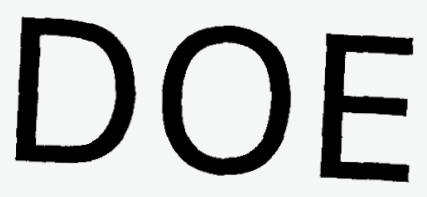

